\title{
Measuring Intercultural Learning through CLIL
}

\section{Elena Gómez-Parra $(1)$}

Departamento de Filologías Inglesa y Alemana, Universidad de Córdoba, Córdoba, Spain

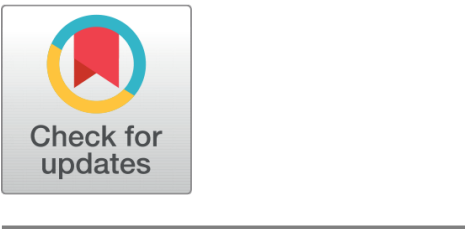

Received 2019-07-13

Revised 2019-09-06

Accepted 2019-10-30

Published 2020-01-15

\section{Corresponding Author}

M. Elena Gómez-Parra,

elena.gomez@uco.es

Universidad de Córdoba, Facultad de Ciencias de la Educación, Avda. San Alberto Magno, s/n, 14071, Córdoba, Spain

DOI https://doi.org/10.7821/ naer.2020.1.457

Pages: 43-56

Distributed under

Creative Commons CC BY 4.0

Copyright: (C) The Author(s)

\section{ABSTRACT}

CLIL (Content and Language Integrated Learning) —endorsed by the European Commission since 1996- constitutes the official approach to bilingual education in Spain. Intercultural learning (IL) is one of the four defining Cs in CLIL, though the literature has consistently described it as the weakest implementation area. This paper analyses the opinions of 76 Spanish secondary education students about IL through their bilingual curriculum. Their viewpoints clearly suggest that IL comes from two main sources: native assistants; and exchange programmes. These data were contrasted with the views of school principals and bilingual coordinators, who declared that both of these valuable 'resources' for IL are scarce due to administrative difficulties and lack of budget. Our conclusions reveal how improving these areas can lead not only to improved scores but also to a better implementation of the intercultural axis in CLIL, if the goal consists in educating $21^{s t}$ century citizens.

\section{INTRODUCTION}

The concept of intercultural education originated towards the end of World War II when the idea that a common national culture should exist was advocated, and various educational policies promoted the integration of minority groups on the basis of compensatory schemes and the teaching of an official language. The term 'intercultural education' has certainly remained controversial ever since. The literature has offered numerous versions thereof, which essentially consist in the addition of different prefixes to the adjective 'cultural' (i.e. 'multi-', 'inter-', 'pluri-', 'trans-'). A certain degree of consensus finally seems to exist in this regard, as explained below:

- 'Multicultural' (almost the same as 'pluricultural') indicates that certain cultural groups live together within a particular society for one reason or another.

- 'Transcultural' means the passage from one culture to another.

- 'Intercultural' refers to a dynamic process in which the individuals involved are aware both of their interdependence and of how important it is to understand each other's cultural constructs so that true coexistence can be ensured.

\section{OPEN ACCESS}


Most international organisms and institutions, including UNESCO and OECD, recognise the need to enhance $21^{\text {st }}$ century students' skills and attitudes to communicate interculturally. In other words, educational programmes and approaches must be purposefully designed to foster the development of individuals' intercultural communicative competence (ICC) — discussed by Byram (1997); Risager (2011) — which consists of knowledge, skills, attitudes, values, and critical awareness.

One of these approaches is CLIL (acronym for Content and Language Integrated Learning), defined by Marsh (2002, p. 15) as "any dual-focused educational context in which an additional language, thus not usually the first foreign language of the learners involved, is used as a medium in the teaching and learning of non-language content". CLIL has been officially endorsed by the European Commission since 1996 and, according to Coyle (2008, p. 98): "In the 1990's, the European Commission was instrumental in promoting a reconceptualisation of these diverse models into the European phenomenon of CLIL - an evolution which has taken over 10 years and is continuing". Moreover, Kramsch (2011a, p. 356), one of the forerunners of intercultural education precepts and of their interdependence when it comes to second/foreign language teaching and learning, established a clear link between intercultural competence and languages, thus confirming a long tradition represented by other scholars who had intensely debated on this connection (see Risager, 2011 for a review of the most important studies in the field). Therefore, since culture and languages (more specifically, interculture and bilingual education in this paper) undoubtedly constitute a binomial, Coyle's (1999, 2002, 2006, 2007) theoretical and practical framework of the four Cs provided CLIL with a powerful tool on which much research and implementation has been carried out. The role of culture, one of these four Cs (which stand for communication, content, cognition, and culture), is seen by Coyle (2009, p. 107) as "a challenging one - not least because of the flexible nature of CLIL and its range of contextual identities, but essentially the relationship between culture and learning in general, and language learning in particular, is open to interpretation and debate". In addition to pursuing an improvement of bilingual students' linguistic competence (Montalto, Walter, Theodorou, \& Chrysanthou, 2016), CLIL has simultaneously and specifically been designed to enhance their intercultural awareness through the positioning of the self and the 'otherness' (Byram, Gribkova, \& Starkey, 2002, p. 10).

Nevertheless, the implementation of the intercultural axis in CLIL becomes controversial due to an array of different factors:

1. Though the intrinsic relationship between culture and language learning is paramount (Kramsch, 1995; 1998; 2013), its nature and how it materialises in educational contexts has been extensively discussed (e. g., Coyle 2009 stated that cultural construct complexity lies at the root of this difficulty).

2. The role of culture within CLIL and the ongoing discussion on the identification of the pedagogical constructs best suited to enhance intercultural communicative competence permanently arises as a hot topic in the literature. Amongst others, Portera (2008) spoke about the role played by the context when it comes to developing appropriate intercultural communicative competence, whereas Holliday, Hyde, and Kull- 
man (2010) agreed that intercultural communication skills prove advantageous when three components are conveyed, namely: identity; 'otherisation'; and representation. The status of the intercultural axis in CLIL remains undisputed, though (Bruton, 2013; Coyle, 2009).

3. Intercultural education must accomplish a variety of goals through bilingual approaches. Marsh, Maljers, and Hartiala (2001) concluded that these programmes help students build self-confidence to contact peers from abroad as well as to overcome potential issues such as racism or social prejudices. Peñalva and Soriano (2010) in turn stated that intercultural education becomes essential to help citizens develop a European identity. For Coyle, Holmes, and King (2009) CLIL students' intercultural competence better prepares them for internationalisation, to which Méndez-García (2012) added the following: "CLIL presents an apparent potential for the development of crucial intercultural attitudes, the vital development of critical cultural awareness, and, finally, action-taking" (p. 196).

The complexity involved in intercultural axis implementation within CLIL has consequently made research focus increasingly on this specific point of analysis, where further and more in-depth studies are needed according to Méndez-García (2012), so that valuable results can be achieved. Most research (Méndez-García, 2014; Sudhoff, 2010) refers to the advantages of using CLIL as a pedagogical approach to enhance learners' intercultural communicative competence Byram (1997) and intercultural understanding.

According to Widdowson (2004, p. 548): "Learning a language involves both getting to know how meanings are encoded into it, and being able to act upon this abstract knowledge to engage in actual behaviour." This materialisation of abstract knowledge takes place through the 'four skills' (speaking, listening, reading, and writing) - an expression originated in the audio-linguistic approach and which the literature shows as being absolutely consolidated in the field of foreign language pedagogy through its adaptation to the communicative method. Teachers have been using it for more than six decades; hence the familiarity of most educational stakeholders with those 'four skills.' When the European Union itself identifies 'communication in foreign languages' as a key competence for lifelong learning, it discriminates between the different skills, as can be seen in their definition of this competence (European Parliament and Council of the European Union, 2006):

It is based on the ability to understand, express and interpret concepts, thoughts, feelings, facts and opinions orally and in writing (listening, speaking, reading, and writing) in a range of social and cultural contexts (such as education and training, private and professional life and leisure) according to one's wishes or needs. Communication in foreign languages also requires skills such as mediation and intercultural understanding. Each person's level of mastery will be different in each of the four dimensions (listening, speaking, reading and writing) and will also vary according to the language concerned and the social and cultural level, the environment, needs and interests of each individual.

European Parliament and Council of the European Union, 2006, p. 14 
Nonetheless, these roots are not at odds with updating the concept, currently developed around two fundamental strands: (a) the intercultural approach, where the understanding of cultural meanings in languages becomes an essential construct to study how languages are learnt; and (b) the technological approach, in which Innovation and Communication Technologies (ICTs) stand as essential pillars from which a new universe is built.

It should likewise be noted that the Council of Europe has established new scales in its recent revision of the Common European Framework of Reference for Languages (CEFR) (Council of Europe, 2018), according to which the different skills are divided into four types of activities, namely: reception, production, interaction, and mediation; and into two competences: communicative linguistic competence; and plurilingual and pluricultural competence.

Conclusions from even more recent research indicate that the implementation of the intercultural axis within CLIL is not being successful (Griva \& Kasvikis, 2014). Amongst others, Ortega-Martín, Hughes, and Madrid (2018) have conducted extensive research on the influence of political factors on bilingual CLIL programmes in Spain which confirms that such schemes do not attach enough importance to intercultural competence development or to language assistants. Moreover, Roiha and Sommier (2018) assert that the participants in their study (former CLIL students) "did not receive formal intercultural communication training during their CLIL education" (p. 12).

Therefore, the role of interculture and the enhancement of intercultural competence amongst students enrolled in bilingual programmes are well built in the literature, along with the important role played by the teacher in the process as a whole.

The theoretical assumptions stemming from this theoretical review - which underpin our study too- can be summarised as follows:

1. Learning second languages improves intercultural communicative practices (Moeller \& Nugent, 2014).

2. Language and culture are closely related (Kramsch, 2011).

3. Teachers' planning and classroom strategies largely influence intercultural communicative practices (Byram et al., 2002).

4. Good knowledge about the first culture improves intercultural communicative practices (Samovar, Porter, Mcdaniel, \& Roy, 2013).

Following the results of the hitherto available literature, our study's next step consisted in analysing the opinions of 76 Spanish CLIL secondary-education (15-to-16-year-old) students about their intercultural gains. A complementary contrastive analysis will enable us to evaluate whether their perceptions concur with those expressed by school principals and bilingual programme coordinators. The latter arise as key educational actors, since they carry out the administrative and academic surveillance of the bilingual curriculum; hence the relevance of their perception to improve students' IL. The interview included specific questions in which they were asked to give their opinion about the extent to which language assistants and international exchanges effectively enhanced students' IL. LindholmLeary (2016) discussed the need to delve deeper into the knowledge of students' perceptions 
in relation to bilingual programmes. Our study adheres to this line and adds a contrastive analysis of principals and bilingual programme coordinators' viewpoints concerning the same topic.

To summarise, this study mainly focuses on analysing the opinions of Spanish secondary education students involved in Spanish bilingual CLIL programmes about the intercultural learning (IL) achieved in those programmes. The aim consists, firstly, in checking if their perception about the implementation of this axis is positive, and secondly, in identifying the factors which, in their opinion, most helped them improve their IL. Thus, the term intercultural learning (IL) will refer here to whether or not students' intercultural awareness improved after specific didactic interventions.

The correlation between intercultural education, bilingual education and intercultural learning (IL) can be found at Gómez-Parra (2018). This author justifies a joint approach to bilingual and intercultural education by following, on the one hand, the main precepts developed by Byram (2012), who confirms the close relationship between language and culture learning and teaching: "in the best cases, language and culture teaching produces -through the development of linguistic and intercultural competence- alternative conceptualisations of the world and contributes to the education/Bildung of the individual in society" (p. 5). On the other hand, European bilingual education relies on the Content and Language Integrated Learning (CLIL) approach, which includes intercultural learning as one of its fundamental axes. Coyle, Hood, and Marsh (2014) conceptualisation of the '4 Cs' framework (Communication, Content, Cognition, and Culture) stands out as a powerful tool to explain how the integration of language and content can only be conveyed through the backbone of this model: culture (i.e. interculture). In her words: "Culture is not a postscript. It is a thread which weaves its way throughout any topic or theme. Sometimes referred to as the 'forgotten C,' it adds learning value to CLIL contexts, yet it demands careful consideration. For our pluricultural and plurilingual world to be celebrated and its potential realised, this demands tolerance and understanding." (Ibid., 2014, p. 54). Thus, the connection between intercultural education, bilingual education and intercultural learning (IL) can be described as interwoven in the sense that bilingual education can only be understood from an intercultural axis (intercultural education) where students' IL should be assessed.

Two main objectives were set to accomplish this main goal: (a) gathering and analysing the opinions of 76 Spanish secondary education students about the IL obtained through their bilingual curriculum from a CLIL scheme; and (b) gathering and analysing the views of school principals and bilingual programme coordinators about the success of the programme in enhancing students' IL, as well on their perception with regard to the value of native language assistants and international exchanges, seeking to contrast their views with the data obtained from students. 


\section{METHOD}

The methodological approach used for this study had a qualitative-quantitative nature, which facilitates a weighted determination of the set of indicators that make up our two instruments.

The first step of our research project - a literature review - allowed us not only to clarify the main concepts but also to update the literature in the field.

Another four methodological steps were designed and followed in order to achieve our established goals.

1. Two specific tools were used: a) A questionnaire based on a 1-to-5 Likert scale (where 1 meant 'No agreement' and 5 meant 'Full agreement') with 4 sections: 1 . Statistical data. 2. A set of 7 questions on language level. 3. A set of 4 questions on IL from bilingual courses. 4. A set of 3 open-ended questions. $b$ ) A structured interview (Fontana \& Frey, 2005) for principals and bilingual programme coordinators with the following blocks: 1. Statistical data. 2. A set of 5 questions on IL and the main resources used both by teachers and by their schools to enhance students' IL.

2. These two instruments were validated according to the Delphi method (Linstone \& Turoff, 2002) with the aim of obtaining a final tool assessed by a panel of experts who had been purposefully chosen according to their domain of expertise (bilingual education and intercultural education). The panel of experts evaluated the aforesaid tools by developing a series of alternatives, exploring or exposing underlying assumptions, as well as through the correlation of judgments on a topic spanning a wide range of disciplines (Hsu \& Sandford, 2007). Internal consistency was used to measure the validity of both instruments according to content validity on the one hand, and to comprehension validity on the other hand. Cronbach's alpha (Cronbach, 1990), served to measure scale reliability, obtaining a value of 0.946 for the first instrument, and 0.924 for the second, both results being classified as very good (Nunnaly \& Bernstein, 1994).

3. After having validated both tools (i.e. the questionnaire and the interview), they were considered suitable for their distribution across the sample population.

4. Lastly, following data collection, the quantitative set was analysed by means of the software IBM SPSS Statistics v. 22, whereas qualitative data were scrutinised through content analysis, "a research method for making replicable and valid inferences from data to their context, for the purpose of providing knowledge, new insights, a representation of facts and a practical guide to action" (Elo \& Kyngä, 2008).

\subsection{Sample description}

The sample of students, gathered during January and February 2019, was formed by 76 students from two bilingual secondary schools located in Southern Spain (see Table 1) randomly chosen amongst those bilingual schools which agreed to participate in the study (n $=15$ ). The condition required for them to participate was to have an operational CLIL programme in the educational centre. They were both were public schools and the students 
from the two cohorts selected (15-to-16-year-olds) were doing their $4^{\text {th }}$ year of Compulsory Secondary Education (ESO - Educación Secundaria Obligatoria). The reason to select this specific group of students was that they were in their last year of the Spanish secondary education stage - a suitable time to evaluate if IL had been successful throughout that period. The coordinators $(n=2)$ and the school principals $(n=2)$ interviewed belonged to the same schools so that data could be properly contrasted.

Table 1 Population statistical data

\begin{tabular}{ll} 
Metacode & Code \\
\hline (1) Sex & $\begin{array}{l}\text { (1.1) Male }=48.68 \% \\
\\
\text { (1.2) Female }=51.32 \%\end{array}$ \\
(2) Age & (1.1) 15 year-olds $=46.05 \%$ \\
& $(1.2)$ 16 year-olds $=53.95 \%$ \\
& (1.1) Spanish $=90.78 \%$ \\
(3) Nationality & $(1.2)$ Non-Spanish $=9.22 \%$ \\
& (1.1) English $=100 \%$ \\
(4) Second Languages & (1.2) French $=69.73 \%$ \\
\hline
\end{tabular}

Student distribution was balanced in accordance with statistical data. All students (= $100 \%$ ) were doing English as a second language, and $69 \%$ of them stated that they were also doing French as a third language in their curriculum.

\section{RESULTS}

Our analysis will focus on the results obtained from sections 3 and 4 of students' questionnaire, since these are the data which can be contrasted with those obtained from the interviews with school principals and bilingual programme coordinators.

\subsection{Results from the questionnaire to students}

The software IBM SPSS Statistics v. 22 served to analyse the quantitative data. The quantitative research findings from the questionnaire distributed amongst the 76 students involved in our study are the following (Table 2):

1. Both the mean $(\mathrm{M}=3.01)$ and the standard deviation $(\mathrm{SD}=3.43)$ of the complete questionnaire indicate that students mostly think that interculture learning (IL) is present across their CLIL programme curriculum.

2. The mean $(\mathrm{M}=2.64)$ and the standard deviation ( $\mathrm{SD}=3.89)$ corresponding to question No. 1 (i.e. "Your bilingual programme includes the participation of students in exchange schemes") reveal that students do not agree with this statement.

3. The mean $(\mathrm{M}=3.71)$ and the standard deviation $(\mathrm{SD}=3.20)$ corresponding to question No. 2 (i.e. "Enough time is devoted to dealing with activities related to culture or interculture") indicate that students agree with this statement.

4. The mean $(\mathrm{M}=3.42)$ and the standard deviation ( $\mathrm{SD}=3.76)$ corresponding to question No. 3 (i.e. "We contact people from abroad for cultural exchanges") show that 
students agree with this statement.

5. The mean $(\mathrm{M}=2.28)$ and the standard deviation $(\mathrm{SD}=2.89)$ corresponding to question No. 4 (i.e. "Teachers have a high cultural knowledge and they teach it in their courses") make it clear that students do not agree with this statement.

\begin{tabular}{lll}
\hline $\begin{array}{l}\text { Table } 2 \\
\text { results }\end{array}$ & Summary of mean and standard deviation \\
& Mean (M) & Standard Deviation (SD) \\
\hline Question 1 & 2.64 & 3.89 \\
Question 2 & 3.71 & 3.20 \\
Question 3 & 3.42 & 3.76 \\
Question 4 & 2.28 & 2.89 \\
\hline
\end{tabular}

Regarding the results for students' answers for the 3 open-ended questions, below can be found the summary of the content analysis carried out:

1. $72.3 \%$ of students $(n=55)$ claimed that the contact with peers from abroad is what they liked most about the IL derived from their CLIL programme.

2. 69 students $(90.7 \%)$ claimed to have obtained most of their IL from the native language assistant who took part in the bilingual programme. A majority of them $(85.52 \% ; \mathrm{n}=65)$ explained that those native language assistants usually show a good cultural/intercultural knowledge.

3. $84.2 \%$ of students $(n=64)$ said that they would like to participate in an exchange programme because, in their opinion, their intercultural awareness had significantly improved thanks to the direct contact with students from abroad $(72 \% ; \mathrm{n}=55)$, or to the international stays with a family $(12 \% ; n=9)$.

\subsection{Results from the interviews with bilingual programme coordinators and school principals}

The qualitative data from the interviews with bilingual scheme coordinators and school principals were scrutinised through content analysis. The 2 coordinators and the 2 school principals interviewed belonged to the same schools to ensure that the data from both samples could be properly contrasted.

According to their statistical data, both school principals $(=100 \%)$ were male. They both had a B2 certified level of English, but neither of them had done a training course on bilingual education. Regarding bilingual coordinators, 1 of them was male and the other one was female ( $=50 \%$ for each value). As for their second languages, they both spoke English; one of them had a C2 level of English, and the other had a C1 level. Neither of them spoke a third language. Finally, both coordinators were teachers of English.

The interview conducted comprised 5 questions on intercultural learning and the main resources used by teachers and their schools to enhance students' IL. 
The first question asked coordinators and principals about their personal opinion with regard to the degree of intercultural learning improvement achieved by students. Both coordinators and both principals $(=100 \%)$ agreed that students had improved their intercultural learning level, and the two bilingual coordinators added that every teacher was aware that CLIL has a cultural component which needs to be instilled through the programme.

The second question focused on the implication of the school board and teachers in international programmes (e.g. eTwinning, Erasmus+). Both the principal and coordinator of the first school said that, although the board supported such programmes, they turn out to be quite inaccessible (even though their school keeps trying at every new call). The other school principal and coordinator told us that they had coordinated several international teacher-and-student-exchange programmes funded by the European Commission for over 20 years. Those experiences had proved really successful in terms of student and teacher involvement, though with a limited number of students, as the budget only covers a maximum of 50-55 students per academic year. The two principals and the two coordinators stressed the difficulty of being selected to obtain funds. In other words, schools have few opportunities to engage students in international exchanges, and self-funding is not an option for the community (school, parents, teachers...). Both principals agreed that schools lack national or regional administration support; more exchange programmes and, accordingly, opportunities for students - should be available.

The answers for the third question ("Do you think international programmes contribute to enhance students' intercultural learning?") showed unanimous agreement $(=100 \%)$ amongst both school principals and both bilingual coordinators.

The fourth question in the interview ("Does the school have a native language assistant for the bilingual programme?") collected the following answers: Both the principal and the coordinator of the first school explained that there was one native teacher (from the UK) who worked full-time at the educational centre. However, the principal and the coordinator of the second school declared that they only had a part-time language assistant (from the USA) -i.e. he taught half of his hours elsewhere. Both of them (the school principal and the coordinator) insisted on the fact that the central administration should invest in this valuable resource. For them, the job of language assistants is very important for the programme when it comes to students' intercultural learning and their practice of oral skills (speaking and listening).

Finally, the fifth item queried principals and coordinators specifically on the role of language assistants as far as IL is concerned within bilingual programmes. They all (=100\%) emphasised the importance of language assistants for the bilingual scheme, insofar as they help students improve their cultural awareness $(=25 \%)$ and intercultural learning $(=75 \%)$.

\section{DISCUSSION}

The results of this study clearly show that, according to students, intercultural learning within bilingual programmes stems from two main sources: on the one hand, their contact with peers through international exchange schemes $(=72.3 \%)$; and, on the other hand, 
the native language assistants $(=90.7 \%)$ who work in these schools. These opinions match the views of the two principals and the two coordinators interviewed, who unanimously agreed that the students involved in the bilingual programme had improved their IL level.

These data contrast to some extent with the results provided so far by the literature with regard to the weaknesses of intercultural axis implementation within CLIL programmes (e.g. Méndez-García, 2012, amongst others). The two cohorts of students interviewed in this study acknowledged some improvement in their IL level. Added to this, they stated that interculture is present across the curriculum of their bilingual programme; they were able to specifically recognise it in the activities related to culture or interculture that formed part of their subjects.

Furthermore, when asked about the source of this IL, students mostly highlighted two of them: international exchange schemes; and language assistants (as most of them assigned a low level of cultural knowledge to bilingual programme teachers). Another important contrast related to data becomes visible here: most of these students declare that they have not participated in exchange programmes. This was confirmed during the interview with the principals and coordinators, who specified that international schemes tend to be quite inaccessible. Even though one of the schools runs them on a regular basis, not many students participate because funding does not suffice for all bilingual students in the educational centre. Therefore, our study population agreed that these programmes are important for the educational community, their relevance for IL enhancement being clearly prioritised by principals, coordinators (both of whom are also teachers of English in their respective schools) and students.

Finally, students recognise the value of language assistants when it comes to improving their IL. For most students ( 69 out of $76=90.79 \%$ ), these native English-speaking teachers played a major role in their IL enhancement. These opinions matched those expressed by principals and coordinators, who highly value the job developed by language assistants, while simultaneously complaining about the short time that those assistants spend in their schools (especially in the case of the principal and the coordinator of the second school). These data are in tune with the results obtained in the study conducted by Ortega-Martín et al. (2018). These authors checked that students highlight amongst the strengths of current CLIL programmes that they have a native teacher each year; that they enjoy exchanges with international schools; that they travel to the country where the target language is spoken; and that they can practise the language with native speakers. All these are clear benefits for IL through bilingual education which our study population (students, principals, and coordinators) has summarised as being related to two different reasons: being offered the opportunity to participate in exchange programmes; and receiving instruction from native language assistants.

\section{CONCLUSIONS}

The main conclusions drawn from this study address the importance of improving the implementation of CLIL's intercultural axis. Seeking to promote foreign language learning, 
educational institutions around the world have set themselves the objective of promoting linguistic diversity and IL in accordance with the CEFR (Council of Europe, 2001, 2018). Though extensive research still needs to be conducted, it clearly seems that Spanish bilingual programmes are beginning to assume how important it is to instil intercultural learning as one of the assets of education. Moreover, bilingual schemes can help preserve minority groups' cultural heritage and linguistic knowledge, since students can more easily become integrated into the mainstream society (Ozfidan \& Toprak, 2019). The results of this paper clearly stress the importance of two key factors for IL within bilingual education, namely: international exchange schemes; and native language assistants. They both were identified by the participants in our study (school principals, bilingual programme coordinators, and secondary education students) as crucial for IL enhancement. School principals and bilingual programme coordinators complained about the scarcity of these two valuable resources, though. In their view, if national and regional administrations devoted more efforts and budget to these areas, it could lead to better performances, and to a significant improvement in the results of CLIL-based intercultural learning.

A number of suggestions could be made to improve students' Intercultural Learning(IL), which not only requires specific didactic planning by teachers but also needs to be purposefully addressed. IL can take place only when teachers and students build a common space for a suitable interaction. Moreover, using these spaces to allow intercultural communication and awareness raising might bear fruit, as stakeholders would find ways of affiliating with each other's learning narratives. Purposeful planning along with the implementation of exchanges, narratives, debates, and assemblies could foster IL inside the classroom. In summary, the possibility exists for IL to be significantly enhanced when teachers bring students closer to communication. In the end, we are all cultural beings and the most natural environment for us lies within communication. Coyle, Hood and Marsh (2014, p. 55) briefly explained it as follows: "CLIL offers rich potential for developing notions of pluricultural citizenship and global understanding - but these need to be planned and transparent (Commission of the European Communities, 2008)."

\section{REFERENCES}

Bruton, A. (2013). Some of the reasons why... and why not. System, 41, 587-597. https://doi.org/ 10.1016/j.system.2013.07.001

Byram, M. (1997). Teaching and assessing intercultural communicative competence. Clevedon: Multilingual Matters.

Byram, M. (2012). Language awareness and (critical) cultural awareness - relationships, comparisons and contrasts. Language Awareness, 21, 1-13. https://doi.org/10.1080/09658416.2011.639887

Byram, M., Gribkova, B., \& Starkey, H. (2002). Developing the intercultural dimension in language teaching. A practical introduction for teachers (and others, Ed.). Strasbourg: Council of Europe. Retrieved from https://rm.coe.int/16802fc1c3.

Council of Europe. (2001). Common European framework of reference for languages: Learning, teaching, assessment. Strasbourg: Council of Europe.

Council of Europe. (2018). Common European Framework of Reference for Languages: Learning, Teaching, Assessment. Companion Volume with New Descriptors. Strasbourg: Council 
of Europe. Retrieved from https://bit.ly/2HogLCH

Coyle, D. (1999). Theory and planning for effective classrooms: Supporting students in content and language integrated learning contexts. In J. Masih (Ed.), Learning through a foreign language: Models, methods and outcomes (pp. 46-62). London: CILT.

Coyle, D. (2002). Relevance of CLIL to the European Commission's language learning objectives. In D. Marsh (Ed.), CLIL / EMILE: The European dimension - action, trends and foresight potential (pp. 27-28). European Comission. Retrieved from https://bit.ly/2WiuNLk

Coyle, D. (2006). Developing CLIL: Towards a theory of practice. In and others (Ed.), Monograph 6 (pp. 5-29). Barcelopa: APAC.

Coyle, D. (2007). The CLIL quality change (D. Marsh \& D. Wolff, Eds.). Frankfurt: Peter Lang.

Coyle, D. (2008). CLIL - A pedagogical approach to CLIL from the European perspective. In N. H. Hornberger (Ed.), Encyclopedia of language and education. 2nd Edition. Second and foreign language education (Vol. 4, pp. 97-111). New York: Springer. https://doi.org/10.1007/ 978-0-387-30424-3

Coyle, D. (2009). Promoting cultural diversity through intercultural understanding: A case study of CLIL teacher professional development at in-service and pre-service levels. In M. L. CarrióPastor (Ed.), Content and language integrated learning: Cultural diversity (pp. 107-124). Berna: Peter Lang.

Coyle, D., Holmes, B., \& King, L. (2009). Towards an integrated curriculum: CLIL national statement and guidelines. Londres: The Languages Company.

Coyle, D., Hood, P., \& Marsh, D. (2014). The CLIL tool kit: Transforming theory into practice. Retrieved from https://bit.ly/2ouluvi

Cronbach, L. J. (1990). Essentials of psychological testing. New York: Harper Collins Publishing. 5th Ed.

Elo, S., \& Kyngä, S. H. (2008). The qualitative content analysis process. Journal of Advanced Nursing, 62(1), 107-115. https://doi.org/10.1111/j.1365-2648.2007.04569.x

European Parliament \& Council Of Europe. (2006). Recommendation of the parliament and of the council of 18 December 2006 on key competences for lifelong learning (2006/962/CE). Official Journal of the European Union, 394(10). Retrieved from http://bit.ly/2wf0WH1

Fontana, A., \& Frey, J. H. (2005). The interview: From neutral stance to political involvement. In N. K. Denzin \& Y. S. Lincoln (Eds.), The Sage handbook of qualitative research (pp. 695-727). Thousand Oaks, CA: Sage Publications Ltd.

Gómez-Parra, M. E. (2018). Bilingual and intercultural education (BIE): Meeting 21st century educational demands. Theoria et Historia Scientiarum, XV, 85-99. https://doi.org/10.12775/ ths.2018.006

Griva, E., \& Kasvikis, K. (2014). CLIL in Primary Education: Possibilities and challenges for developing L2/FL skills, history understanding and cultural awareness. In $N$. Bakić-Mirić \& D. E. Gaipov (Eds.), Current trends and issues in education: an international dialogue. Cambridge Scholars Publishing. Retrieved from http://bit.ly/2hyLJgo

Holliday, A., Hyde, M., \& Kullman, J. (2010). Intercultural communication: An advanced resource book for students. London: Routledge.

Hsu, C. C., \& Sandford, B. A. (2007). The Delphi technique: making sense of consensus. Practical assessment research and evaluation, 12(10), 1-8.

Kramsch, C. (1995). The cultural component of language teaching. Language, Culture and Curriculum, 8(2), 83-92. https://doi.org/10.1080/07908319509525192

Kramsch, C. (1998). Language and culture. Oxford: Oxford University Press.

Kramsch, C. (2011). The symbolic dimensions of the intercultural. Language Teaching, 44, 354-367. https://doi.org/10.1017/S0261444810000431 
Kramsch, C. (2011a). The symbolic dimensions of the intercultural. Language Teaching, 44, 354-367. https://doi.org/10.1017/S0261444810000431

Kramsch, C. (2013). Culture in foreign language teaching. Iranian Journal of Language Teaching Research, 1(1), 57-78.

Lindholm-Leary, K. (2016). Students' perceptions of bilingualism in Spanish and Mandarin dual language programs. International Multilingual Research Journal, 10(1), 59-70. https://doi.org/ $10.1080 / 19313152.2016 .1118671$

Linstone, H. A., \& Turoff, M. (2002). The Delphi Method. Techniques and applications. Reading, MA: Addison-Wesley Publishing Company.

Marsh, D. (2002). CLIL/EMILE - The European dimension: Actions, trends and foresight potential. Retrieved from https://jyx.jyu.fi/bitstream/handle/123456789/47616/1/david_marsh-report .pdf

Marsh, D., Maljers, A., \& Hartiala, A. K. (2001). Profiling European CLIL classrooms: Languages open doors. Jyväskylä: University of Jyväskylä.

Méndez-García, M. C. (2012). The potential of CLIL for intercultural development: a case study of Andalusian bilingual schools. Language and Intercultural Communication, 12(3), 196-213. 10.1080/14708477.2012.667417

Méndez-García, M. C. (2014). The intercultural turn brought about by the implementation of CLIL programmes in Spanish monolingual areas: A case study of Andalusian primary and secondary schools. The Language Learning Journal, 41(3), 268-283. https://doi.org/10.1080/ 09571736.2013 .836345

Moeller, A. J., \& Nugent, K. (2014). Building intercultural competence in the language classroom. In S. Dhonau (Ed.), Unlock the gateway to communication. 2014 report of the central states conference on the teaching of foreign languages (pp. 1-19). Richmond: Johnson Litho Graphics of Eau Claire, Ltd.

Montalto, S., Walter, L., Theodorou, M., \& Chrysanthou, K. (2016). The CLIL guidebook. CLIL4U (and others, Ed.). Retrieved from https://bit.ly/2NosMcx

Nunnaly, J. C., \& Bernstein, I. H. (1994). Psychometric theory (3rd ed.). New York: MacGraw Hill Inc. 3rd edition.

Ortega-Martín, J. L., Hughes, S., \& Madrid, D. (2018). Influencia de la política educativa de centro en la enseñanza bilingüe en España. Madrid: Ministerio de Educación, Ciencia y Deporte.

Ozfidan, B., \& Toprak, M. (2019). Cultural awareness on a bilingual education: A mixed method study. Multicultural Learning and Teaching, 14(2), 1-10. https://oi.org/10.1515/mlt-2017 $-0019$

Peñalva, A., \& Soriano, E. (2010). Objetivos y contenidos sobre interculturalidad en la formación inicial de educadores y educadoras. Estudios sobre Educación, 8, 37-57.

Portera, A. (2008). Intercultural education in Europe: Epistemological and semantic aspects. Intercultural Education, 19(6), 481-491. https://doi.org/10.1080/14675980802568277

Risager, K. (2011). The cultural dimensions of language teaching and learning. Language Teaching, 44, 485-499. https://doi.org/10.1017/S0261444811000280

Roiha, A., \& Sommier, M. (2018). Viewing CLIL through the eyes of formal pupils: insights into foreign language and intercultural attitudes. Language and Intercultural Communication, 18(6), 1-18. https://doi.org/10.1080/14708477.2018.1465069

Samovar, L. A., Porter, R. E., Mcdaniel, E. R., \& Roy, C. S. (2013). Communication between cultures (8th ed.). Wadsworth: Cengage Learning. 8th edition.

Sudhoff, J. (2010). CLIL and intercultural communicative competence: Foundations and approaches towards a fusion. International CLIL Research Journal, 1(3), 30-38.

Widdowson, H. G. (2004). Skills and knowledge in language learning. In M. Byram (Ed.), Routledge 
Encyclopedia of Language Teaching and Learning (pp. 548-553). Abingdon: Routledge. 